\title{
Reconhecimento étnico afrodescendente Considerações sobre os processos jurídicos no Brasil e Colômbia
}

\author{
Reconocimiento étnico afrodescendiente. \\ Consideraciones sobre los procesos juridicos en Brasil y Colombia
}

\author{
Ethnic afrodescendant Recognition. \\ Considerations about legal process in Brazil and Colombia
}

\author{
Marlon Marcelo ${ }^{1}$ \\ Leonardo Henrique ${ }^{2}$
}

\begin{abstract}
Resumo
O texto apresenta e analisa, de forma breve, o panorama de implementação de leis que versam sobre o reconhecimento étnico no Brasil e na Colômbia, examinando as diversas colonialidades em jogo na elaboração, implantação e execução dos direitos étnicos afrodescendentes em ambos os países. $\mathrm{O}$ artigo se orienta a partir das implicações nas comunidades beneficiadas dentro do novo marco multicultural adotado pelas nações latinoamericanas nas últimas décadas, permitindo assim que identifiquemos os problemas e as atuações dos Estados frente à visibilidade e ao reconhecimento dos grupos afrodescendentes em contexto nacional, e percebemos como vinculados ao sistema mundo colonial/moderno. Pretendemos esboçar o cenário de manobras políticas, as medidas de austeridade econômica, os planos governamentais neodesenvolvimentistas, além de outros fatores e atores que influem dentro e fora das comunidades na construção de acesso aos seus direitos. Ademais, intentamos refletir sobre as múltiplas faces da colonialidade dentro do funcionamento dos Estados brasileiro e colombiano, buscando uma análise comparativa que possa contribuir para novos horizontes na discussão da presença e participação das comunidades negras na esfera pública e política nacional. Por fim, destaco as experiências jurídicas e de políticas públicas no âmbito legislativo e executivo que influem diretamente sobre as mobilizações, atuações e respostas das comunidades às práticas de Estado e do Capital no espaço latinoamericano.
\end{abstract}

Palavras-Chave: Direitos étnicos, reconhecimento, colonialidade, afrodescendentes, Brasil, Colômbia

\section{Resumen}

El texto presenta y analiza, de forma breve, el panorama de implantación de leyes que versan sobre el reconocimiento étnico en Brasil y Colombia, examinando las diversas colonialidades en juego en la elaboración, implantación y ejecución de los derechos étnicos afrodescendientes en ambos los países. El artículo se orienta a partir de las implicaciones en las comunidades beneficiadas adentro del nuevo marco multicultural adoptado por las naciones latinoamericanas en las últimas décadas, que permite identificar los problemas y las actuaciones de los Estados frente a la visibilidad y reconocimiento de los grupos afrodescendientes en el contexto nacional y los percibo como vinculados al sistema-mundo colonial/moderno. Pretendo esbozar el escenario de manobras políticas, las medidas de austeridad económica, los planes gubernamentales neodessarrollistas entre otros factores y actores que influyen dentro y fuera de las comunidades en la construcción de acceso a sus derechos. Además, reflexiono sobre las múltiples faces de colonialidad adentro del funcionamiento de los Estados brasileño y colombiano, buscando un análisis comparativo que contribuye para nuevos horizontes en la discusión de la presencia y participación de las comunidades negras en la esfera pública y política nacional. En suma, destaco las experiencias jurídicas y de

\footnotetext{
${ }^{1}$ Graduando em Antropologia; Universidade Federal de Minas Gerais;; Belo Horizonte, Minas Gerais, Brasil; Marlonmarcelo.s@gmail.com. Trabalho apresentado no I Seminário Latino-Americano de Estudos em Cultura SEMLACult, Foz do Iguaçu/PR, Brasil, 2017.

${ }^{2}$ Bacharel em Economia Doméstica; Universidade Federal de Viçosa - UFV; Viçosa, Minas Gerais, Brasil leonardo_hcm@yahoo.com.br.
} 
políticas públicas, en el ámbito legislativo y ejecutivo, que influyen directamente sobre las movilizaciones, actuaciones y respuestas de las comunidades a las prácticas de Estado y del capital en el espacio latinoamericano.

Palabras claves: Derechos étnicos, reconocimiento, colonialidad, afrodescendientes, Brasil, Colombia

\section{Abstract}

This article presents and briefly examines the horizon of law implementation regarding ethnic recognition in Brazil and Colombia, analyzing the numerous 'colonialities' present in the elaboration, implementation and execution of ethnic afrodescendant rights in both countries. The article is directed by the implications to the benefited communities within a new multicultural mark adopted by Latin-American countries in the last decades, points the problems and actions of the States towards the visibility and recognition of the afrodescendant groups in a national context while understanding them as linked to the colonial/modern world system. We talk about political maneuvers, economic austerity measures, and governmental neodevelopmentalist plans, among others, as actors that do influence the inside and outside of these communities, while trying to have their rights recognized. Moreover, we reflect about the multiple faces of coloniality as it works in Brazilian and Colombian States, aiming to analyze them comparatively to contribute to the debate with new horizons about the presence and participation of black communities in the public spaces and national politics. Lastly, this work highlights the juridical experiences and public policies, in the legislative and executive spaces, that influence directly the mobilizations, actions and responses of the communities to the practices of the State and Capital in the LatinAmerican context.

Keywords: ethnic rights, recognition, coloniality, afrodescendants, Brazil, Colombia.

\section{Introdução}

Este artigo é resultado de reflexões e questionamentos suscitados durante minha estadia na Universidad Nacional de Colombia ${ }^{3}$, no segundo semestre de 2016, também no decorrer da minha trajetória acadêmica na participação de projetos e disciplinas que envolvem a temática. Este trabalho pretende esboçar um panorama da implantação de políticas de reconhecimento étnico, sobretudo das comunidades afrodescendentes no Brasil e na Colômbia a partir das teorias pós-coloniais e da decolonialidade desenvolvida por teóricos indianos e latino-americanos nas últimas décadas.

A promulgação de leis e constituições nos últimos trinta anos visam os direitos étnicos das populações subjugadas no processo colonizador e apresenta um novo momento da história desses povos perante os Estados Latino americanos. Todavia, essas novas políticas estão inseridas em um sistema de relações entre movimentos locais e questões globais. As políticas de reconhecimento étnico estão situadas em um contexto de globalização, no qual há processos assimétricos entre local e global. Como agentes da globalização os povos lutam

\footnotetext{
${ }^{3}$ Realizada por meio de intercâmbio acadêmico e cultural financiado pela Fundação Universitária Mendes Pimentel. Durante os meses do intercâmbio, cursei algumas disciplinas na Universidade dediquei-me à entender algumas questões fundamentais das populações afrocolombianas.
} 
para re-definir suas identidades pessoais e coletivas. Os subalternizados não são sujeitos passivos a uma lógica cultural externa, mas pessoas que negociam ativamente suas identidades através de estratégias culturais de resistência (CASTRO-GOMEZ \&MENDIETA, 1998).

Os movimentos sociais são agentes que reconfiguram os cenários políticos por meio de suas identidades e de lutas contra exclusão social, buscando visibilização e reconhecimento. Essas sociedades políticas reorientam a lógica hegemônica no sentido de (re)existir em termos que não condizem com o movimento de ocidentalização promovido pelo desenvolvimentismo (CHATTERJEE, 2004). A luta por identidades perante o Estado e pela territorilização de lugares, em contraposição à lógica de espaços abstratos promovidos pelo capital, constituem trincheiras da resistência, pois buscam visibilibilzar suas experiências em meio ao movimento de apagamento dos sujeitos pelo capital (ZHOURI, 2015).

Essas inovações constitucionais além de serem respostas a lutas políticas, internas e externas aos Estados nacionais, são produtoras de novas realidades. Elas inserem os grupos envolvidos em uma nova ordenação jurídica e política produzindo mudanças significativas nos âmbitos locais. Ademais, propõe novas lógicas, nas quais essas comunidades se veem inseridas e induzidas a se articular politicamente a partir delas. Desse modo, esses decretos promovem uma rede de processos complexos que se interpelam no decorrer do reconhecimento, da mobilização política e administrativa tanto dos Estados como das próprias comunidades.

A criação de leis de reconhecimento na Colômbia, como no Brasil, está inserida em uma série de acordos assinados em convenções internacionais. Como signatários da convenção $\mathrm{n}^{\circ} 169$ da Organização Internacional do Trabalho de 1989, os países sulamericanos ficaram responsáveis por criar políticas que buscassem reconhecer a diversidade cultural dos grupos do território nacional, como também assegurar sua reprodução sociocultural. Dentre essas políticas estava o reconhecimento e demarcação de territórios tradicionais. Assim, a formulação de decretos e leis no contexto colombiano e brasileiro também se insere em um conjunto de respostas a demandas globais que buscam conciliar a expansão do capitalismo e a salvaguarda de direitos sociais. Dessa maneira, a promulgação dessas leis ainda está vinculada ao sistema-mundo colonial/moderno (GOSSFOGUEL, 2008), pois vão de acordo com a manutenção de lugares de poder, com a expansão do capitalismo e a sujeição dos grupos a lógicas externas. 
Não obstante, essas leis provocam atitudes subversivas às ações do Estado e de outros agentes globais. Elas suscitam a construção de novas identidades em políticas, (MIGNOLO, 2008, pg. 290) que partem de lugares étnico-raciais subalternos e tem o potencial de descolonizar práticas e pensamentos. Essas comunidades se veem em novos âmbitos e transitam entre as organizações políticas de caráter institucional e nas autoridades eleitas localmente. Elas aprendem a dialogar e articular um jogo político próprio que visa assegurar direitos e liberdades, além de defender suas epistemologias frente à epistemologia colonial/moderna.

No decorrer do texto apresento um panorama geral da promulgação da lei 70 de 1993, que garante os direitos territoriais e étnicos às populações negras no contexto colombiano, e das leis de reconhecimento étnico no Brasil. Posteriormente, desenvolvo algumas considerações sobre suas respectivas implementações e sobre a atuação de diversos atores econômicos, políticos e sociais na esfera comunitária e judicial. Para o exercício em questão foi utilizado bibliografias referentes à temática de reconhecimento étnico e perspectivas críticas desde o sul global, aplicando uma análise às políticas de ambos os países latinos americanos.

\section{O caso colombiano}

O reconhecimento étnico afrodescendente na Colômbia se insere na agenda multiculturalista promovida na construção da constituição nacional de $1991^{4}$. Os antecedentes à promulgação da lei 70 de 1993 são marcados pelas lutas de movimentos sociais e pelas disputas políticas entre grupos étnicos colombianos. A expedição da lei se ancorou no artigo transitório 55 da constituição de 1991, a primeira carta magna do país a reconhecer a natureza pluriétnica e multicultural da nação. Essas inovações tinham como objetivo conduzir o processo interno de paz e aumentava o número de interlocutores da sociedade civil para fazer frente à guerrilha. Também sofreu forte influência das lutas das comunidades indígenas, as quais se mobilizavam desde a década de 1960 para representação no texto constitucional. Os

\footnotetext{
${ }^{4}$ A referida constituição foi reconhecida no meio acadêmico colombiano como constituição multicultural e hoje é um dos centros de discussão da existência de conflitos entre os diversos grupos habitante do espaço agrário do país. Para saber mais: ARROCHA, 1992
} 
trabalhos preliminares da constituinte foram acompanhados por diversos representantes de grupos étnicos colombianos principalmente aqueles que advogavam pela causa negra. ${ }^{5}$

Esses trabalhos tinham a finalidade de construir um texto que propusesse o reconhecimento dos indígenas, negros e outros grupos étnicos. O resultado foi a aprovação do Artigo Constitucional Transitório 55 que previa a criação de uma comissão especial para elaborar o projeto de lei que regulamentaria os direitos territoriais das populações negras rurais da costa do pacífico. Também foi regulamentado o reconhecimento das populações indígenas em outro artigo da constituição. Portanto, a lei 70 foi promulgada no sentido de regulamentar o artigo 55 de 1991 e em conjunto outras normas foram decretadas para melhor gerir essas políticas, dentre elas: políticas de educação, de propriedade e de representatividade.

De acordo com o artigo $1^{\circ}$ do texto de 27 de agosto de 1993 o decreto define que:

\begin{abstract}
La presente ley tiene por objeto reconocer a las comunidades negras que han venido ocupando tierras baldías en las zonas rurales ribereñas de los ríos de la Cuenca del Pacífico, de acuerdo con sus prácticas tradicionales de producción, el derecho a la propiedad colectiva, de conformidad con lo dispuesto en los artículos siguientes. Así mismo tiene como propósito establecer mecanismos para la protección de la identidad cultural y de los derechos de las comunidades negras de Colombia como grupo étnico, y el fomento de su desarrollo económico y social, con el fin de garantizar que estas comunidades obtengan condiciones reales de igualdad de oportunidades frente al resto de la sociedad colombiana. ${ }^{6}$
\end{abstract}

No decorrer do texto do decreto são descritos as definições das regiões que abrangem a lei, o direito a propriedade coletiva, os usos dos recursos naturais, diretrizes para planejamento de proteção e desenvolvimento dos direitos e da identidade cultural. Como já citado, outros decretos em conjunto com a lei foram promulgados com fins de complementar as políticas voltadas para/a esses grupos. Alguns exemplos são: o decreto 1.745 que regulamenta o direito de Propriedade Coletiva, o decreto 2.249 que criava um instituto de pesquisas responsável pela etno-educação e o decreto 2.314 que previa a representação dessas comunidades negras e indígenas no interior dos organismos governamentais de desenvolvimento.

\footnotetext{
${ }^{5}$ Destaco a luta do Proceso de comunidades negras (PCN) que mobilizou diversos atos públicos e presença massiva nas audiências da formulação do artigo transitório 55 de 1991.

${ }^{6}$ Para leitura completa da lei acessar:http://www.alcaldiabogota.gov.co/sisjur/normas/Norma1.jsp?i=7388 acessado 27/06/2016
} 
A lei dos negros, como ficou conhecida, deflagrou uma série de mudanças estruturais na organização do Estado e nas mobilizações políticas das comunidades. Uma nova política fundiária passou a vigorar, transformações nas concepções de uso das terras e no acirramento de disputas territoriais com grandes empresas e guerrilhas. No campo acadêmico houve grande incentivo nos estudos sobre populações negras colombianas, área que antes era negligenciada pelos pesquisadores contando com uma parcela muito pequena de especializados. Esse contexto foi responsável pela implementação da cadeira de estudos afrocolombianos nos níveis de educação básica primária e secundária, nas instituições públicas e privadas (AROCHA, 2009). Esse movimento também permitiu a abertura de um novo campo de estudos com novos paradigmas de pensamento nos meios universitários, onde as questões como racismo, exclusão social e questões culturais negras tornaram-se centrais nos debates acadêmicos (SAA, 2008).

$\mathrm{Na}$ esfera política os movimentos cimarrones, negros, palenqueros e raizales ${ }^{7}$ ganharam força se articulando para conseguir a efetivação de vários direitos ancorados no corpo da lei de reconhecimento. Ela serviu e ainda serve de luta para outras populações negras que estavam fora das regiões que o texto jurídico previa inicialmente. Diversos grupos reivindicaram o reconhecimento como afrocolombiano como foi o caso das populações das proximidades de Cali, Antioquia, Cartagena e Bogotá. No caso das populações ao redor da cidade de Cartagena, os grupos utilizaram a lei para lutar contra a expansão da indústria turística, que ameaçava as terras e o bem estar dos povoados locais. Além disso, outros temas foram levantados para o debate no cenário nacional como questões que deveriam ser colocadas e resolvidas, sobretudo o racismo que a população afrodescendente sofria na sociedade colombiana. As questões de reconhecimento produziram um "entrelazamiento" de temas relacionados a situações das populações negras que desestabilizaram a unidade cultural e os mitos da ideologia de mestiçagem, democracia racial, unidade linguística e religiosa pregado desde o republicanismo do século XIX (ARROCHA, 2009; SILVA, 2012).

\section{O caso brasileiro}

A promulgação do texto constitucional brasileiro em 1988 foi considerada um avanço no que se refere aos direitos humanos e à proteção da diversidade cultural. Os artigos

\footnotetext{
${ }^{7}$ Divisões internas do movimento pelo reconhecimento dos afrodescendentes na Colômbia. Eles se diferem a partir de características identitárias próprias e regiões específicas do país. Para saber mais: GRUESO, 2001; LEIVA ESPITIA, 2013
} 
215 e 216 da constituição preveem o reconhecimento, a proteção e a salvaguarda de manifestações culturais das matrizes que sofrearam com maior intensidade o processo colonizador e assimilador nacional. O reconhecimento dessas outras matrizes, além da europeia, na formação da nação abriu um campo para a discussão sobre as populações remanescentes de quilombos e possibilitou a viabilidade de um reconhecimento para acesso a direitos fundamentais. No artigo 68 dos atos das disposições constitucionais transitórias (ADCT) da carta magna, o Estado reconhecia a propriedade definitiva das terras ocupadas pelos remanescentes das comunidades de quilombo e assegurava a emissão dos respectivos títulos. Essa abertura promoveu o surgimento de um escopo jurídico próprio para o tratamento das questões étnicas no país nos âmbitos territoriais indígenas e negros. Tal legislação previa a demarcação de territórios étnicos e a criação de uma estrutura institucional responsável pelo reconhecimento, delimitação e demarcação de territórios quilombolas no país. Ademais, outros decretos foram promulgados a fim de executar políticas públicas para essas comunidades. Esta conquista de direitos referentes aos povos indígenas e quilombolas articulou uma mobilização de movimentos sociais que defendiam o reconhecimento de diversas outras categorias identitárias. Esse fato culminou no reconhecimento jurídico-formal de novas categorias de "povos e comunidades tradicionais", considerando a diversidade dos contextos socioambientais existentes no país.

Nos anos seguintes, esse tema se tornou um tópico destacável na agenda política internacional. Convenções, congressos e instituições internacionais buscaram constituir políticas que promovessem a sustentabilidade e o desenvolvimento dessas comunidades. Os artigos $6^{\circ}$ e $7^{\circ}$ da convenção 169 da OIT de 1989 orientaram a formulação de um programa jurídico que protegesse a diversidades social e cultural das populações afrodescendentes do país a partir da participação desses povos na arena política nacional. Na esfera internacional o Brasil também foi signatário da Convenção da diversidade biológica de 1992, que passou a vigorar no Brasil em 1998, e preconizava a conservação da biodiversidade e da proteção das comunidades tradicionais que viviam em estreita relação com os recursos naturais. É possível perceber esse aspecto no inciso I do artigo $8^{\circ}$ onde expressa: "Procurar proporcionar as condições necessárias para compatibilizar as utilizações atuais com a conservação da diversidade biológica e a utilização sustentável de seus componentes", e no artigo 10: "letra c) Proteger e encorajar a utilização costumeira de recursos biológicos de acordo com práticas culturais tradicionais compatíveis com as exigências de conservação e utilização sustentável;". 
Em âmbito nacional, o cumprimento desses acordos internacionais foi determinado pelo decreto presidencial $\mathrm{n}^{\circ} 4.887$, de 20 de novembro de 2003, que regulamentava os processos de identificação, reconhecimento, delimitação e demarcação dos territórios quilombolas. Neste contexto, os processos fundiários para demarcação das terras e emissão de títulos foi vinculada ao Instituto nacional de colonização e reforma agrária (INCRA), no qual foi criada uma comissão interna ao órgão para constituir uma estrutura burocrática e jurídica para o reconhecimento territorial e social afrodescendente. $\mathrm{O}$ mesmo decreto instaura um plano de desenvolvimento sustentável para os grupos, como também espaços de diálogo na arena pública para proposição de projetos. Além desse decreto, o Brasil assinou a convenção sobre a proteção e promoção da diversidade das expressões culturais no ano de 2007, a qual determinou seu cumprimento no decreto $\mathrm{n}^{\circ} 6.177$, de 1 de agosto de 2007. Para mais, outros mecanismos jurídicos foram assinados posteriormente, como a lei $n^{\circ} 10.678$ de 2003, que cria a secretaria especial de políticas de promoção da Igualdade racial (SEPPIR) e a lei $\mathrm{n}^{\circ} 12.288$ de 2010 , que institui o estatuto da igualdade racial.

No que tange ao trato das comunidades quilombolas, o Estado brasileiro tem adotado uma postura consideravelmente abrupta. Por um lado as políticas econômicas, que oscilaram entre o desenvolvimentismo e o neoliberalismo, incentivaram os megaempreendimentos e o avanço da fronteira agrícola. Por outro, na seara jurídica, ocorreu a desconstitucionalização e a desestruturação de diversos decretos e que possibilitavam a proteção aos povos e comunidades tradicionais, sobretudo as comunidades remanescentes de quilombo. O cenário político atual deflagra um conflito de direitos, represálias e restruturações que inviabilizam o seguimento das atividades dos órgãos públicos. As interrupções políticas e mudanças de governo nos últimos meses aceleraram os processos de desconstitucionalização dos direitos quilombolas, reordenou as ações e os vínculos dos órgãos responsáveis pela demarcação de terras afrodescendentes. A dissolução de ministérios importantes para causa agrária e social foi um mecanismo estratégico para o reordenamento das políticas fundiárias e consequentemente o reconhecimento de terras remanescentes de quilombo. O decreto 8.780 de 27 de maio de 2017 transferiu para casa civil o Incra e outros 3 órgãos relacionados a agricultura com a justificativa que tais instituições deveriam estar mais próximos as decisões do poder executivo, além de ser de interesse nacional, no entanto tal mudança permite que mais uma vez as políticas de visibilidade e reconhecimento estarem sujeitas a interesses econômicos dos atores que compõe o corpo institucional do Estado.

Outro fato que afeta diretamente o caráter jurídico dos grupos afrodescendentes foi a comissão parlamentar de inquérito (CPI) instaurada no ano de 2015 com objetivo apurar 
as ações de órgão responsáveis pela identificação e demarcação de terras quilombolas. Esta comissão acusa o Incra e Funai de atitudes inconstitucionais e questiona a objetividade nos processos jurídicos-administrativos executados por elas. A primeira CPI iniciada em abril de 2015 não logrou a aprovação do relatório final ocasionando o arquivamento do processo. Entretanto, um ano depois, em abril de 2016, uma nova comissão foi formada, com um documento de acusação mais elaborado, para reavaliar as ações e processos internos dentro das secretárias do Incra e da Funai. Com dissensos dentro do próprio congresso, o relatório final da CPI foi publicado em junho de 2017 com a acusação de 67 pessoas, dentre elas: promotores, atores dos movimentos sociais, antropólogos e comunitários. O deputado responsável pelo relatório final, chefe da bancada ruralista do congresso, defendeu na publicação que os comunitários envolvidos nos processos de reconhecimento têm direito a decisão na utilização da terra para fins comerciais e produtivos, além da concessão e contratos. Este fato culminou em manifestações de diversas ordens dos movimentos quilombolas e indígenas de todo o país, pois de acordo com suas concepções esse mecanismo promove a precarização dos instrumentos de participação dos grupos dentro dos espaços de decisão. Ademais, sujeita os grupos indígenas e quilombolas a uma série de relações de clientelismos presente no espaço agrário brasileiro, no qual há uma correlação de forças assimétricas entre grandes latifundiários e comerciantes e as comunidades tradicionais. $\mathrm{Na}$ medida em que o poder público age de maneira arbitrária, promove uma afronta aos direitos fundamentais e a precarização dos instrumentos de participação e de luta dos movimentos étnicos nacionais.

O que se verifica na prática no Brasil é a afronta constante e sistemática aos direitos dos povos tradicionais, patrocinada pelos empreendimentos minerários, pela criação de unidades de conservação, pela monocultura de eucalipto, pela construção de barragens e pelo desenvolvimento de grandes obras de infraestrutura, além das manobras políticas corruptas no cenário das instituições do Estado. As localidades se veem transformadas repentinamente pela lógica do Estado/Capital, que opera de modo pouco ou nada participativo e os povos tradicionais são a parcela mais vulnerável neste contexto.

A face mais visível deste processo se dá na relação com as comunidades remanescentes de quilombo. As denúncias de ameaças aos indígenas e povos quilombolas são frequentes assim como os conflitos possessórios no processo de implementação de empreendimentos minerários, unidades de conservação e monocultura. Esses grupos são muitas vezes expulsos de suas terras sem qualquer indenização. Este cenário de acosso aos direitos fundamentais vai em direção contrária da legislação brasileira de 1988. 


\section{As faces da colonialidade}

A invasão das Américas pelos europeus iniciou um processo de classificação dos povos em raças como também a realização do projeto da modernidade. Desse modo, a colonialidade é parte constituinte da modernidade, pois o projeto moderno europeu só foi possível por meio da negação das alteridades outras que emergiram a partir do novo continente. A colonização se deu em dois âmbitos: o temporal, marcado pelo movimento anglo-saxão e que instituiu o advento da ciência como conjunto de ideias norteadoras; e o espacial, ligado aos povos ibéricos que desumanizaram os outros povos (MIGNOLO, 2003, pg.678). O colonialismo europeu nas Américas promoveu a subjugação das populações autóctones, a migração compulsória, desestabilização e segregação da população negra no continente.

Aníbal Quijano (2005) aponta que a globalização é fruto de um processo que se iniciou na constituição da América e do capitalismo colonial/moderno. Assim a América surge como a primeira id-entidade moderna e evoca um novo padrão de poder mundial eurocentrado. Por meio do julgo colonial a codificação entre conquistadores e conquistados conformaram a classificação do mundo na ideia de raça. A partir de justificativas biológicas e fenópticas essa racialização subjulgou outros povos- ameríndios, negros e afrodescendentes a uma alteridade negada (DURSSEL,2005).

No julgo colonial essas populações foram alijadas de quaisquer direito sobre as terras que habitavam, seus corpos e sua cultura. O processo de constituição da América está vinculado a "todas as formas de controle e de exploração do trabalho e de controle da produção-apropriação-distribuição de produtos foram articuladas em torno da relação capitalsalário (de agora em diante capital) e do mercado mundial" (QUIJANO, 2005, pg.228). Esse fato constitui um novo padrão global de controle do trabalho e consequentemente um elemento de um novo padrão de poder. O controle do trabalho se articula com uma raça em particular, essa divisão racista perpetua posições de poder e reitera a violência das práticas colonizantes.

Uma questão interessante a se destacar é que uma das convenções mais influentes na proposição das políticas de reconhecimento está relacionada ao trabalho. A convenção 169 da OIT, que foi base para a implantação de normas de reconhecimento étnico em vários países, inclusive Brasil e Colômbia, orienta as políticas nacionais que de certa maneira circunscrevem 
um universo de pessoas e culturas em categorias racializadas no e para o capitalismo mundial. Outro aspecto é a implantação de decretos, como é o caso da lei 70 na Colômbia e os decretos paras comunidades remanescentes de Quilombos no Brasil, estão imbuídos de discursos desenvolvimentistas que não condizem às expectativas das comunidades. Essa chave recai sobre discursos para o desenvolvimento de suportes tecnológicos e participação cidadã e reitera posições coloniais presentes na instituição dessas políticas.

O processo de implantação da lei 70 no território colombiano foi marcado de controvérsias. Foram criadas instancias de decisão para cumprir o que previa a lei 99 de 1993, aonde ascendia as comunidades ao estatuto de co-formuladoras e gestoras de planos, programas e projetos de desenvolvimento que envolvesse seus territórios. No entanto, essas instâncias "em nome de estarem reconhecendo a legitimidade de estruturas "tradicionais", como foi dito, parecem estar produzindo novos padrões de organização que vão se impor ao plano local." (ARRUTI, 2000, pg. 98). Ademais, a lei 70 propõe uma leitura da cultura negra nos termos das culturas indígenas associando os dois grupo a mesmos valores e características. Desse modo, o Estado colombiano classifica os afrocolombianos por meio de ideias preestabelecidas com diacríticos raciais determinados.

O corpo da lei define as diretrizes de categorização, classificação, planejamento, manutenção e mobilização das comunidades e organizações do Estado. Em primeiro momento esses escopo se define por circunscrever as comunidades a espaço geográfico especifico do Pacífico colombiano, dificultando o acesso aos direitos referidos por outras comunidades fora deste particularismo geográfico predeterminado (HOFFMAN, 2000 pg.4). Outro problema se destaca no que o antropólogo Eduardo Restrepo denomina de Riocentrismo (RESTREPO, 2005 pg.36) que cria uma relação direta do negro as bacias hidrográficas do Pacifico colombiano desconsiderando outras possibilidades de existência fora dessa paisagem natural.

Nos discursos que plantearam os projetos de reconhecimento e visibilidade afrodescendente na Colômbia se basearam a partir de um discurso da biodiversidade como objeto de planejamento e controle estatal de terras ainda não exploradas. Esses espaços, em conjunto com as comunidades, servem de estratégias para uma futura acumulação capitalista, baseada na exploração de recursos químicos, genéticos e biológicos (ESCOBAR, 1997). Os grupos surgem no discurso institucional do Estado como protetores naturais do meio ambiente e enraizados na terra, como parte dela e que devem responder às suas instituições, a partir de representações próprias que sejam inteligíveis ao corpo burocrático e jurídico. Tal fato reitera 
a necessidade do Capital, junto com a estrutura pública do Estado, de controlar áreas marginais, esta entendidas como regiões habitadas por minorias étnicas onde o Estado tem um atuação débil. ( WADE, 2010).

No caso colombiano, os conflitos armados e ações repressivas por parte do Estado aos grupos armados provocaram a formigação de terrenos de cultivo e deslocamento em massa de grande parte da população campesina da região pacífica. Esses deslocamentos causam o aumento das periferias das grandes cidades e a precarização das condições de vida desses grupos afrodescendentes no contexto urbano. Produzindo uma relação cíclica de despejo das regiões rurais e assistencialismo a periferia majoritariamente negra nas urbes do país. As comunidades negras rurais, dentro da expansão capitalista, são vistas como atrasadas e se tornam um obstáculo para o desenvolvimento econômico do país (ESCOBAR, 2003). Desse modo, os projetos que visam o desenvolvimento comunitário são visto como urgentes para execução de interesses de exploração dessas áreas que até então não foram alcançadas. A construção de redes de caráter étnico permite um maior diálogo com os atores locais e os sujeitam a um jogo de decisões arbitrárias dentro dos espaços institucionais que se distanciam de uma possibilidade de produção de projetos que promoveram um real benefício às comunidades. A violência exercida sobre os povos negros rurais são constantes desde a segunda metade do século XX quando o Estado colombiano incentivava o fluxo de imigrantes para as regiões do pacífico com intuito de realizar projetos de reordenamento territoriais para aproveitamento de recursos naturais. Isso acirrou os conflitos já existentes entre comunidades negras e indígenas da região. Com uma face ambígua o Estado colombiano promoveu ações violentas às comunidades afrocolombianas e atualmente busca reconhecer suas existências em um ato de tornar legíveis os modos de ser e viver dessas comunidades (DAS \& POLLE, 2008).

No entanto, a legibilidade das populações negras foi um processo complexo. O corpo normativo, as organizações de representatividade e os discursos oficiais sobre os afrocolombianos inicialmente eram equiparados as realidade indígenas desconsiderando as diferenças sociais e estruturais dessas sociedades. As comunidades negras foram inseridas em lógicas de organização que não condiziam as suas organizações locais, foram lidas em silogismos que partem de uma duvidosa analogia a situação indígena (ARRUTI, 2000, Pg.97). As comunidades negras eram sempre vistas como grupos intermediários entre a agricultura monetária branca e a agricultura de subsistência indígena assumindo o lugar de principais agentes locais do processo de avanço do Estado e do Mercado. Logo, as políticas voltadas 
para as populações negras colombianas são permeadas pela colonialidade do poder (QUIJANO, 2005), que operam a partir de um patrão de específico da modernidade no qual há uma naturalização das hierarquias raciais e sociais e um sistema de exploração vinculada ao padrão global de poder capitalista.

Ao instituírem legalmente termos identitários o Estado instaura novos seres nos discursos jurídicos, acadêmicos, políticos e administrativos. Essas identidades interpelam as comunidades e passam a fazer parte da vida de seus integrantes. As estruturas de poder definem como e quando devem ser implantados projetos e outras atuações nessas comunidades. No decorrer do processo a colonialidade do poder se evidencia a partir do controle da direção das decisões, a inserção em lógicas de poder distantes das comunidades e acirramento de conflitos entre as próprias comunidades. O reconhecimento identitário e étnico define a existências de outros seres por meio de definições arbitrárias..

Perante os contextos de negociação política, grandes empreendimentos e disputas fundiárias, no Brasil e na Colômbia, é importante discutir como se caracterizam esses escopos jurídicos e administrativos e suas fragilidades no que cerne a implementação e articulação pelas comunidades afetadas. Os embustes burocráticos provocam mudanças estruturais na mobilização política comunitária como também a insere em um plano complexo de leituras identitárias e sociais feitas pelo Estado.

Ao longo dos processos de implementação de projetos que violam os direitos coletivos, diversas práxis de coação vão surgindo com finalidade de deslegitimar e desestruturar os grupos tradicionais. Através de relatórios técnicos, reuniões extraordinárias e uso do capital econômico, os empreendedores se articulam na esfera pública e privada para efetivar a obra. Na esfera pública os acordos entre as partes vão constituindo uma rede de interesses comuns que desconsidera as populações afrodescendentes como cidadãos e os trata apenas como populações passíveis a deslocamento e compensação. Como aponta Partha Chattajee, a emergência das democracias de massa nos países industriais produziram duas distinções de legibilidade em sua estrutura.

É a distinção entre cidadão e populações. Cidadãos habitam o domínio da teoria, populações, o domínio das políticas públicas. Diferentemente do conceito de cidadão, o conceito de população é totalmente descritivo e empírico; não traz nenhuma carga normativa. Populações são identificáveis, classificáveis e descritíveis por critérios empíricos e comportamentais, e são abertas a técnicas estatísticas, tais como censos e pesquisas amostrais (CHATTERJEE,2004,p.107).

Os territórios tradicionais se tornam objetos de interesses políticos que podem transitar entre a legitimidade e na ilegitimidade. Elas se tornam "entraves" no 
desenvolvimento e caracterizam como obstáculos para a realização de uma agenda progressista. Em diversas ocasiões os megaempreendimentos e negociações de conflitos, em especial o caso dos conflitos armados colombianos, são inclusive utilizados como trunfos eleitorais e como forma de manutenção de poder político.

É possível inferir que a agenda econômica desenvolvimentista que os últimos governos latino-americanos têm implementado vem acompanhada de instrumentos formais que possibilitam a sua execução. Isto equivale dizer que a legitimação dos empreendimentos e a desestruturação formal dos mecanismos de reconhecimento se dão por meio de políticas públicas e atos administrativos que oferecem, em última instância, a aparente legalidade que tais atos necessitam.

Importante destacar que as universidades, em ambos os contextos, também se situam dentro do corpo institucional do Estado e são fundamentais na construção dessas leituras políticas e administrativas. As teorias e debates travados no interior das academias são apropriados e articulados num plano de relações que envolvem comunidade, Estado (este entendido como instituições de caráter jurídico e administrativo) e capital (setores privados que transitam nas diversos espaços do Estado e das comunidades). Portanto, é importante apresentar de que maneira o Estado torna legível as comunidades e suas existências. Esse ato se ancora em uma relação de hegemonia na qual também é uma "relação pedagógica de construção de novos sujeitos sociais e políticos" (BIANCHI,2007, pg.11). Elas apresentam o ser comunitário como um consenso, um conceito circunscrito em determinados critérios, além de orientar suas práticas e vivências políticas, ainda que estas comunidades extrapolem estas nomenclaturas e conceitos. Dessa forma, o cenário político e administrativo se torna um espaço de negociação onde as correlações de forças estão em constante disputa.

Uma legislação especifica e a atuação de gestores muitas vezes com ações interessadas no campo das negociações desmitifica os tipos ideias propostos na sociologia do Estado weberiana. Os estados latino-americanos estão distantes de possuir um caráter impessoal e funcional organizados em posições hierárquicas (status) com medidas metódicas para a realização dos deveres oficiais (WEBER, 1974). Este Estado é fruto de relações de poder que a todo o momento se chocam entre si. A eficiência da execução das leis e resolução dos problemas esta sujeita a conhecimento das leis e da boa vontade de executá-las, desse modo o Estado se daria pelas correlações entre os diversos âmbitos do social, o Estado é na verdade "a prática refletida dos homens" (FOUCAULT, 2008, pg.330). Como Foucault (2008) ainda ressalta o Estado não é um agente, mas produto das relações. Portanto, as 
relações traçadas dentro das instituições públicas estão concernentes a interesses econômicos e políticos dos atores que as compõem. Um dos exemplos são os relatos e ações do deputado responsável pelo relatório final da CPI- INCRA e FUNAI 2, instituída em 2016, que além de exercer cargos públicos, tem interesses diretos no agronegócio e na implantação de latifúndios em terras tradicionais indígenas e quilombolas. A criminalização de órgãos e atores envolvidos nas causas indígenas e quilombolas, através de mecanismos jurídicos formais, evidenciam as diversas estratégias de deslegitimação dos direitos coletivos e as práticas de manutenção das posições de poder. Ela expõe como se dá os processos decisórios e quais atores tem peso na produção política de reconhecimento.

A atuação das instituições do Estado em relação às políticas de reconhecimento afrodescendente conformam práticas singulares que visam, ou não, tutelar esses grupos. As atuações muitas vezes desconsideram as realidades ou as trata como meros problemas burocráticos sem resolução prévia. Assim, o Estado busca gerir (SOUZA LIMA, 2002) esses grupos como apenas sujeitos de políticas e não de fato atores no processo de construção política. Segundo o autor

\begin{abstract}
No momento atual, assistimos à ênfase numa "nova" articulação entre "sociedade civil" e "Estado", sob um ideário da "participação popular", da presença dos "movimentos sociais" (e suas "organizações não-governamentais"), no cenário montado pela grande narrativa da "democratização"[...] Unem-se modalidades de construção de interdependências, sob a forma de organizações, redes e comunidades, oriundas de diferentes tradições de conhecimento, para gestão de desigualdades entre segmentos da população que, no longo prazo, reportam-se ao período colonial. Refiro-me a formas sociais marcadas nas relações pessoais e práticas clientelísticas (Bezerra, 1995,pg. 1999), quando superpostas aos "métodos racionais" da "democracia participativa", reproduzindo-se em novas bases os princípios de associação presentes ao que chamei, impressionisticamente, de "clientalismo de Estado". (SOUZA LIMA, 2002, pg. 18)
\end{abstract}

Logo, o jogo de interesses no Estado são fatores destacáveis de análise. As relações construídas através desse contexto jurídico administrativo se dão a partir de um quadro de negociações e interdependências evidenciadas por Antônio Carlos de Souza Lima. Os direitos coletivos estão sujeitos às oscilações econômicas e as atuações do corpo legislativo e executivo, de modo que são definidos a partir disputas internas as instituições. A criminalização dos órgãos evidencia as negociações e o caráter diverso existente dentro do corpo institucional do Estado.

A produção documental vem ao encontro de legitimar práticas políticas que visam desestruturar as lutas e conquistas logradas pelas comunidades nas últimas décadas. Elas ignoram os outros modos de pensar politicamente e de se organizar das comunidades 
formatando-as aos meios institucionais que não condizem a sua maneira de articular. Este processo reitera as relações de clientelismo e com elas as relações de controle oriundas do período colonial. A autodeterminação prevista na legislação de reconhecimento no Brasil, mecanismo pelo qual permitia as comunidades se articularem politicamente frente a processos expropriatórios, foi o principal elemento atacado nas comissões parlamentares de inquérito. Ao serem julgadas como produtoras de quilombos subjetivos, a autodeterminação, de acordo com os deputados, abriam suspeitas de inconstitucionalidade.

A necessidade de averiguar a identificação e delimitação de "quilombos subjetivos", citados na CPI, afronta o principal mecanismo que possibilita a ação política das comunidades. O documento e o aparato jurídico se tornaram o campo de disputa econômica e política para a precarização e desestruturação dos textos que asseguram os direitos coletivos no Brasil. Não obstante, vale também destacar as ações realizadas pelas mobilizações comunitárias que utilizam o caráter documental como símbolo de legitimação de práticas dentro do Estado e também para efetuar a legibilidade daqueles que estão em suas margens (DAS \& POOLLE,2008). O ato de se adentrar na lógica institucional do Estado, através das funções de conselhos, capitanias, associações seria, portanto, se apropriar das estratégias de governamentabilidade para assegurar direitos fundamentais para suas sobrevivências (FOUCALT, 2008).

\section{Considerações finais}

A diversidade étnico-cultural latino-americana é fruto de diversos contextos locais e regionais oriundos do contato entre grupos étnicos distintos formando especificidades culturais singulares em cada localidade. Entretanto, a formação histórica e social dos Estados latino-americanos se deu a partir de correlações de forças políticas e administrativas arbitrárias. O processo colonizador europeu beneficiou grupos sociais específicos e promoveu uma exclusão sociopolítica de diversos outros povos. A administração colonial subordinou grupos, etnias e populações implantando segregacionismo ou na forma mais radical o extermínio. Com intuito de integrar a uma lógica, o processo de assimilação à sociedade nacional invisibilizou na arena política do Estado esses grupos diferenciados culturalmente, como também os relegou a exclusão ao acesso a diversos direitos assegurados pela constituição.

No decorrer do século XX eclodiram inúmeros movimentos sociais que lutam pelo reconhecimento de direitos e pela visibilidade política nos espaços de decisão. Os novos 
modelos de luta social se inserem em uma dinâmica de redistribuição, reconhecimento e representação nos meios de participação legitimados (MONETNEGRO, 2016 pg.6). Um dos discursos presentes nas lutas era a proteção, por parte do Estado, da reprodução de suas práticas sociais e culturais. A partir da mobilização social enfrentavam as decisões estatais que ameaçavam seu bem estar social, como também reivindicavam reconhecimento politico frente às manobras administrativas promovidas pelos governos. Os principais confrontos eram contra os interesses econômicos do Estado, especialmente, a expansão de grandes empreendimentos. Os movimentos indígenas tiveram grande destaque nessas mobilizações e foram responsáveis pelo incentivo e estruturação de outros movimentos políticos sociais de grupos que se encontram silenciados por pressões econômicas, fundiárias, em processo de discriminação e exclusão social, como é o caso dos movimentos negros.

Esses grupos historicamente excluídos na formação dos Estados nacionais latinos americanos se conformaram como margens que desestabiliza os discursos oficiais de nação e unidade cultural. $\mathrm{O}$ reconhecimento dessas identidades vem de encontro com a produção de legibilidades para o Estado (DAS \& POLLE, 2008) que por sua vez pode reconfigurar os discursos e inseri-los dentro de uma nova lógica de classificação, ainda sim racializada. Essas classificações podem ser problemáticas em alguns aspectos, pois estão inseridas dentro da lógica do sistema-mundo capitalista colonial/moderno. Ainda desencadeia outras violências, principalmente, no processo de inserção dessas comunidades nos locais de gestão ou decisórios, pois desqualifica e desconsidera as múltiplas formas como essas comunidades se organizam politicamente e as coloca no modo de decisão burocrático do Estado.

No entanto, essas políticas podem ser um instrumento para as lutas locais e de uso estratégico contra as forças do capitalismo e do desenvolvimento. Portanto, essas políticas devem ser analisadas em diferentes aspectos, na perspectiva do Estado e das comunidades. $\mathrm{O}$ reconhecimento, de certa maneira, pode evocar descentramentos na forma de perceber as populações subalternizadas pela colonização e constrói possíveis transmodernidades (DURSSEL, 2005) e modernidades alternativas (ESCOBAR, 1995). Elas motivam desobediências a epistemologias dominantes, por que permitem a formação de autonomias dessas comunidades. As demandas globais interpelam os locais que se contrapõem os movimentos homogeneizantes. A lei 70 e as leis para comunidades quilombolas provocaram a retomada de olhares para o local no sentido de dar mais ênfase as constituições e territorializações ocorridas no interior das nações. Essa retomada se expandiu para outras localidades permitindo que grupos se reconhecessem como negros e frutos da colonialização. 
Os movimentos locais no Pacifico, Antioquia, na bacia do Rio Cauca e Magdalena, nas proximidades de Cartagena, na costa caribenha, e em grandes cidades do país repensaram revigoraram suas posições como agentes de mudanças e de produção de saber. Isso se deu também nos espaços rurais e urbanos do Brasil, aonde as populações afrodescendentes vem reordenando as posições de poder ao desvelar os discursos raciais existentes desde a colônia.

A memória da escravidão e dos negros na Colômbia e no Brasil foi reanimada não para fins de reproduzir o sofrimento, mas abrir novas possibilidades para se pensar a nação e as contribuições dessas populações na formação sociocultural do país. Além do mais mobilizou os atores negros a orientar suas vidas de outras maneiras valorizando aquilo que tinham como base cultural. Os palenques e quilombos se tornaram símbolo da (re) existência do negro no contexto colombiano e brasileiro, pois foi o espaço da liberdade e livre expressão. Para mais o palenque privilegia o pensamento do local em detrimento de localidades abstratas globais, pois é o lugar da memória do negro, do escravizado, da luta, da fuga e da trajetória dos africanos nas terras americanas. Ele reitera as lutas contra a opressão ocorridas em Cauca, Chocó, Magdalena, dentre outros espaços que constituíram a resistência do povo negro a opressão do sistema colonial e republicano.

\section{Referências bibliográficas}

AROCHA, Jaime. Invisibilidad y espejos para las ciudadanías afrocolombianas en debate. In: A contra corriente A journal on Social History in Litarature in America Latina. Vol. 6, No. 2, Winter 2009, 191-211

AROCHA, Jaime. "Los negros ante la nueva Constitución de 1991", en América Negra, No. 3, Bogotá, Universidad Javeriana, 1992.

ARRUTI, José Maurício Andion. Direitos étnicos no brasil e na colômbia: notas comparativas sobre hibridização, segmentação e mobilização política de índios e negros. Horizontes Antropológicos, Porto Alegre, ano 6, n. 14, p. 93-123, nov. 2000

BIANCHI, Álvaro. Gramsci além de Maquiavel e Croce: Estado e sociedade civil nos "Quaderni del carcere". Utopìa y Praxis Latinoamericana, Mar 2007, vol.12, no.36, p.35-55.

CHATTERJEE, Partha. "Populações e sociedades políticas"; "A política dos governados". In:Colonialismo, modernidade e política. Salvador: EDUFBA, CEAO. 2004.

CASTRO-GOMEZ, Santiago. Ciências sociais, violência epistêmica e o problema da invenção do outro. In Edgardo Lander (org). A colonialidade do saber: eurocentrismo e ciências sociais, perspectivas latinoamericanas. Coleccion Sur-Sur, CLACSO, Ciudad Autônoma de Buenos Aires, Argentina. setembro 2005. Disponible en la World Wide Web: http://bibliotecavirtual.clacso.org.ar/ 
CASTRO-GOMEZ, Santiago \& MENDIETA, Eduardo. Introducción: La translocalización discursiva de Latinoaméricra en tiempos de la globalización". In: Teoria sin disciplina (latinoamericanismo, poscolonialidad y globalización en debate), 1998

CORONIL, Fernando. Natureza do pós-colonialismo: do eurocentrismo ao globocentrismo. In Edgardo Lander (org). A colonialidade do saber: eurocentrismo e ciências sociais, perspectivas latinoamericanas. Coleccion Sur-Sur, CLACSO, Ciudad Autônoma de Buenos Aires, Argentina. setembro 2005. Disponible en la World Wide Web: http://bibliotecavirtual.clacso.org.ar/

DAS, Veena \& POOLE, Deborah - El Estado y sus márgens. Revista Académica de Relaciones Internacionales, núm. 8 junio de 2008, GERI-UAM.

DUSSEL, Enrique. Europa, modernidade e eurocentrismo. In Edgardo Lander (org). A colonialidade do saber: eurocentrismo e ciências sociais, perspectivas latinoamericanas. Coleccion Sur-Sur, CLACSO, Ciudad Autônoma de Buenos Aires, Argentina. setembro 2005. Disponible en la World Wide Web: http://bibliotecavirtual.clacso.org.ar/

ESCOBAR, Arturo. Culture sits in places: reflections on globalism and subaltern strategies of localization. In: Political Geography 20 139-174, 2001

ESCOBAR, Arturo. Displacement, Development, and Modernity in the Colombia Pacific. International social science journal, 55 (1) p. 157- 167, 2004

GRUESO, Libia; Carlos Rosero y Arturo Escobar. 2001. "El proceso de organización de comunidades negras en la región sureña de la costa Pacífica de Colombia". En: Arturo Escobar, Sonia Álvarez y Evelina Dagnino (eds.), Política cultural y cultura política. Una nueva mirada sobre los movimientos, p: 235-260.

LEIVA ESPITIA, Andrea. "Raizal people is our name, self determination is the game": la reivindicación de la identidad raizal, una etnografía de la acción colectiva y los desafíos de la multiculturalidad, en: Restrepo, E (ed.). Estudios afrocolombianos hoy: aportes a un campo transdisciplinario. Popayán: Editorial Universidad del Cauca. 2013, p: 133-158.

MIGNOLO, Walter. DESOBEDIÊNCIA EPISTÊMICA: A OPÇÃO DESCOLONIAL E O SIGNIFICADO DE IDENTIDADE EM POLÍTICA. Cadernos de Letras da UFF - Dossiê: Literatura, língua e identidade, no 34, p. 287-324, 2008 .

MIGNOLO, Walter. "Os esplendores e as misérias da "ciência": Colonialidade, geopolítica do co-nhecimento e pluri-versalidade epistémica. IN: ". In: Boaventura Sousa Santos (org) Conhecimento Prudente para uma Vida Decente. São Paulo: Ed. Cortez, 2003.

QUIJANO, Anibal. Colonialidade do poder, eurocentrismo e América Latina. In Edgardo Lander (org). A colonialidade do saber: eurocentrismo e ciências sociais, perspectivas latinoamericanas. Colección Sur-Sur, CLACSO, Ciudad Autónoma de Buenos Aires, Argentina. Setembro 2005.

SAA, Theodora Hurtado. Los estudios contemporáneos sobre población afrocolombiana. In: Revista CS. Pags 75-99, 2008

SILVA, Vera Regina Rodrigues da. Entre quilombos e Palenques: Um estudos antropológicos sobre políticas públicas de reconhecimento no Brasil e na Colômbia, 2012. 292 fls. (Doutorado em Ciências sociais) - USP. São Paulo, 2012 
SOUZA LIMA, Antônio Carlos.- "Sobre gestar e gerir a desigualdade". Estudos para uma antropologia da administração pública no Brasil. Rio de Janeiro: Nuap/Relume-Dumará, 2002

WADE, Peter. Liberalismo, raza y ciudadanía en Latinoamerica. In: Debates sobre ciudadanía y políticas raciales en las Américas Negras. Bogotá:Universidad Nacional de Colombia. 2010.

ZHOURI, Andréa. Colonialidade, Modernidade e Meio Ambiente. In: V SEMINÁRIO INTERNACIONAL DA PÓS-GRADUAÇÃO EM SOCIOLOGIA DA UNIVERSIDADE FEDERAL DE SÃO CARLOS, 2015, São Carlos, Anais V.1 p. 130- 147 